\title{
Burden of NCDs in SNNP region, Ethiopia: a retrospective study
}

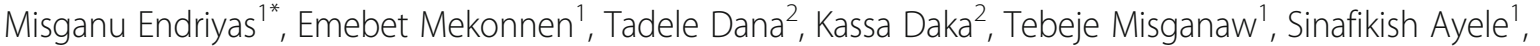 \\ Mekonnen Shiferaw', Tigist Tessema ${ }^{1}$ and Tewodros Getachew ${ }^{2}$
}

\begin{abstract}
Background: Non-communicable diseases (NCDs) are medical conditions or diseases that are non-transmissible. As NCDs are becoming one of major public health problem, providing local description of diseases and injuries is key to health decision- making and planning processes. So, this study aimed to describe caseload of NCDs in Southern Nations Nationalities and People's Region, Ethiopia.

Methods: A facility based retrospective study was conducted in February 2015 in SNNPR, Ethiopia. A total of 22,320 records of three years retrieved from 23 health facilities using systematic sampling. Data were entered in to Epi-Info 3.5.3 and descriptive analysis was carried out using SPSS version 20.

Results: From 22,320 records reviewed, 6633 (29.7\%) clients visited health facilities due to Non-Communicable Diseases (NCDs). Majority (37.2\%) of NCD cases were in productive age groups (20-35 year). Near to half (43\%) of NCD cases were from rural and $45.8 \%$ were females. Digestive disorder (26.7\%), cardiovascular diseases (18.8\%) and Diabetes Mellitus (13.1\%) were the most prevalent types of NCDs.

Conclusion: Health facilities are burdened with significant proportion of clients with NCDs. Young population accounts large share and NCDs are becoming public health problem of urban and rural area within a health care system that focus on communicable diseases. There is a need to strengthen the health system to work towards NCDs, and investigate risk factors associated with NCDs at individual level.
\end{abstract}

Keywords: Non-communicable diseases, Digestive disorder, Cardiovascular diseases, Diabetes mellitus, SNNPR, Ethiopia

\section{Background}

Non-communicable diseases (NCDs) are medical conditions or diseases that are non-transmissible [1]. Cardiovascular diseases, cancers, chronic respiratory diseases and diabetes are the four leading types of NCDs [1-3]. Risk factors for NCDs are categorized in to modifiable (behavioral), metabolic and physiological risk factors. Modifiable behavioral risk factors comprise tobacco use, physical inactivity, unhealthy diet and harmful use of alcohol [1]. An important way to reduce NCDs is to focus on lessening above mentioned risk factors, early detection and timely treatment [4].

NCDs are one of the major health problems and in 2015 , it was reported that they were responsible for $68 \%$

\footnotetext{
* Correspondence: misganuendrias@yahoo.com

${ }^{1}$ SNNPR Health Bureau, Hawassa, Ethiopia

Full list of author information is available at the end of the article
}

of the world's deaths [5]. Almost three quarters of all NCD deaths and the majority $(82 \%)$ of premature deaths occur in low- and middle-income countries [5]. In African nations, NCDs are rising rapidly $[4,6-8]$ and are projected to exceed communicable, maternal, perinatal, and nutritional diseases as the most common causes of death by 2030 [4]. World Health Organization (WHO) 2014 country profile reported that about $30 \%$ of total deaths in Ethiopia were associated with NCDs from which cardiovascular diseases, cancers, chronic respiratory diseases, diabetes, and others NCDs accounted for $9,6,3,1$ and $11 \%$ respectively. It was also estimated that the probability of dying between ages 30 and 70 years from the four main NCDs was 15\% [9].

Despite these facts, these diseases have not been given adequate attention due to the overwhelming burden of infectious diseases [6]. In the context of epidemiologic

(c) The Author(s). 2018 Open Access This article is distributed under the terms of the Creative Commons Attribution 4.0 International License (http://creativecommons.org/licenses/by/4.0/), which permits unrestricted use, distribution, and reproduction in any medium, provided you give appropriate credit to the original author(s) and the source, provide a link to the Creative Commons license, and indicate if changes were made. The Creative Commons Public Domain Dedication waiver (http://creativecommons.org/publicdomain/zero/1.0/) applies to the data made available in this article, unless otherwise stated. 
transition in Ethiopia, a double burden of disease is already emerging with mix of persistent communicable disease and increasing NCDs [10, 11]. However, the burden of NDCs is believed to be under estimated due to lack of reliable data and lack of disease registration system $[8,11]$.

A reliable description of diseases (health conditions) and their risk factors is an important input to planning and decision- making $[12,13]$. But considerable proportion of countries (including Ethiopia and study region) have little usable mortality data and weak surveillance systems $[4,11]$. So, this study was carried out to provide local evidence on burden of NCDs (in terms of caseload) to inform decision-makers and improve planning on NCDs in Southern Nations Nationalities and People's Region (SNNPR), Ethiopia.

\section{Methods}

Facility based retrospective study was conducted in SNNPR Ethiopia in February, 2015. SNNPR is the third largest administrative region in the country and is the most diverse region in terms of language, culture and ethnic background. Administratively the region is divided into 14 zones, 1 city administration and 4 special woredas. Woreda, equivalent to district, is government administrative structure in zone with approximately 100,000 population while special woreda is woreda directly accountable to region, not contained in zone. Based on 2007 census, the region had an estimated population of 18.9 million in 2014 [14]. According to regional health bureau 2013/2014 annual report, there were a total of 21 governmental hospitals, 703 health centers and 3835 health posts [15]. Health posts mainly perform preventive activities at community level while health centers perform both curative and preventive activities leading (on average) 5 satellite health posts in their catchment.

Considering existing logistics $[16,17]$, a total of 23 health institutions were included. Facilities were from 12 zones, 1 special woreda and 1 city administration and were geographically representative. Since majority of health centers in the region were relatively new (not well equipped to diagnose NCDs), capacity of health facilities to diagnose and treat NCDs was considered as inclusion criteria. Government (hospitals and health centers) and private (hospitals and higher clinics) facilities that diagnose and treat NCDs based on physician and laboratory investigation were included in the study.

Three years (2012-2014) clients' records were reviewed. Sample size for clients' card review for single facility per year was calculated by using the single population formula as follows

$$
n \geq\left[\frac{z \alpha / 2}{E}\right]^{2} p(1-p)
$$

Where $\mathrm{n}$-sample size, $\mathrm{P}$ - proportion of population (prevalence), Z- reliability coefficient and d- margin of error. Using $P=30 \%$ as WHO 2014 report stated $30 \%$ national disease burden were due to NCDs [9], $Z=1.96$ reliability coefficient for $95 \%$ confidence interval and $d$ $=0.05$, sample size for a facility per year was 323 . Since we reviewed three years record, 969 records were expected to be reviewed from each facility. Rounding 969 to 1000 , final sample size was 23,000 .

As malaria was endemic and seasonal in some areas in Ethiopia [18] and in SNNPR, major transmission season (September to December) records were not included as malaria epidemic may influence true burden of cases flow. So, we considered records from January to April.

Because of the challenge to review individual client card from medical record unit (card room) due to its arrangement, mixing, lacking level and even missing in some facilities, we used registers to review caseloads. We collected all registration books from all departments (inpatients, outpatients, maternal and child, specialty, emergencies etc....) and counted cases in each registration books over defined study periods and then sample size for each year was allocated for registration books based on cases registered on registers. Finally, the allocated sample size was reviewed using systematic random sampling. During review, records with incomplete, missing or un-readable data were replaced with next records to compensate sample size and continued until specified sample size was filled.

We extracted socio-demographic data, final diagnosis and outcome (alive/dead). For multiple health conditions, specialists were consulted to classify main diagnosis. Records with death outcome were collected without confirming death certification as there was no certification system.

Diseases (health conditions) were classified into: Group I (communicable diseases); Group II (non-communicable causes); and Group III (injuries) and Group IV (maternal conditions and nutritional deficiencies). The magnitude of diseases/conditions attributable to each group were computed.

Data was collected by 11 trained data collectors who have bachelor in health officer or nursing using structured and pre-tested checklist. Data entry and cleaning was done using Epi Info version 7 while descriptive analysis was done using IBM SPSS version 20 for windows. Data cleaning was done by going through the variables one by one and cross tabulating to check for any inconsistencies and out-lying values. Errors during data entry were resolved by going back to the original checklist. Frequencies and percentage of different variables were computed and the results were presented using tables and figures.

Ethical clearance was obtained from SNNPR health bureau Ethical Review Committee. Administrative permission was obtained from regional health bureau and 
zonal health departments. Verbal consent was obtained from heads of health facilities and data handlers after clear explanation of the purpose of the study. No individual identifier data was collected and all information collected was kept confidential.

\section{Results}

\section{Overview of health facilities and study population}

A total of 23 health facilities (15 government hospitals, 1 private hospital, 3 government health centers and 4 private higher clinics) were included in this study. These health facilities were selected from 12 zones, 1 special woreda and 1 city administration indicating facilities were geographically representative to the region. From these facilities, 22,320 records were reviewed.

About half (50.8\%) of clients were females. The age of clients ranged from birth to 99 years with mean of 26.5 years (SD 16.9). The age distribution of clients showed a large number of clients were in age group of 20-35 (39.4\%) and under 5 years old (11.6\%). From total records, 13,203 (59.1\%) clients were from urban areas and $8924(40.3 \%)$ were from rural areas while $193(0.9 \%)$ had missing records of residence (Table 1).

Table 1 Distribution of sex, residence and age category of clients in SNNPR, 2012-2014

\begin{tabular}{|c|c|c|c|}
\hline Variable & Category & Frequency & Percent \\
\hline \multirow[t]{2}{*}{ Sex } & Male & 10,985 & 49.2 \\
\hline & Female & 11,335 & 50.8 \\
\hline \multirow[t]{3}{*}{ Residence } & Rural & 8924 & 40.0 \\
\hline & Urban & 13,203 & 59.1 \\
\hline & Missing & 193 & 0.9 \\
\hline \multirow[t]{18}{*}{ Age } & $<5$ & 2587 & 11.6 \\
\hline & $5-9$ & 1337 & 6.0 \\
\hline & $10-14$ & 1164 & 5.2 \\
\hline & $15-19$ & 2009 & 9.0 \\
\hline & $20-24$ & 3330 & 14.9 \\
\hline & $25-29$ & 3270 & 14.7 \\
\hline & $30-34$ & 2179 & 9.8 \\
\hline & $35-39$ & 1719 & 7.7 \\
\hline & $40-44$ & 1342 & 6.0 \\
\hline & $45-49$ & 992 & 4.4 \\
\hline & $50-54$ & 802 & 3.6 \\
\hline & $55-59$ & 398 & 1.8 \\
\hline & $60-64$ & 473 & 2.1 \\
\hline & $65-69$ & 247 & 1.1 \\
\hline & $70-74$ & 241 & 1.1 \\
\hline & $75-79$ & 82 & 0.4 \\
\hline & $80+$ & 148 & 0.7 \\
\hline & Total & 22,320 & 100.0 \\
\hline
\end{tabular}

\section{Cause of visit}

Of 22,320 records, leading cause of visit was infectious diseases which accounted 11,847 (53.1\%), followed by NCDs 6633 (29.7\%). However, when cases of NCDs added with injuries, figure exceeded one-third (37.1\%) (Table 2).

\section{Description of NCDs}

Large number $(37.2 \%)$ of clients with NCDs were in age range of 20 and 34 years old and more than half (57.0\%) were living in urban areas (Table 3). Female to male sex ratio showed slight difference $(0.86)$, male contributing $54.2 \%$ of total NCD cases.

Of 6633 NCDs reviewed, digestive disorders (26.8\%), cardiovascular diseases (18.8\%) and diabetes mellitus (13.1\%) were top three NCDs among others (Table 4).

Majority of under-five clients with NCDs, 150 (85.3\%), were diagnosed in hospitals and only 8 (4.5\%) were diagnosed in health centers from which half were chronic respiratory diseases.

The proportion of NCDs from total clients was compared over facility levels and differences were noted among primary, secondary and tertiary levels. Percentage of NCDs in tertiary hospital was twice that of secondary (general) hospitals. About one fourth of clients (24.8\%) in primary health facilities and more than half of clients (59.7\%) in tertiary hospital had at least one of NCDs. The trend of NCDs in all levels changed slightly over three years (Fig. 1). In addition, proportion of clients with NCDs were higher in private facilities (1665 (34.9\%)) as compared to government owned facilities (4968 (23.8\%)).

\section{Outcome}

From total records, 72 deaths registered from which more than half, 42 (58.3\%), were females. Moreover, 32 (44.4\%) and 25 (34.7\%) clients who were died came to health facilities due to infectious and NCDs respectively (Table 5). A high number of deaths were observed among under five children and 25-29 years old young group which accounted $21(29.2 \%)$ and $12(16.7 \%)$ respectively. More than half $38(52.8 \%)$ of all deaths registered came from rural areas.

Table 2 Distribution of diseases/conditions among clients, SNNPR, 2012-2014

\begin{tabular}{lll}
\hline Disease/illness/health condition & Frequency & Percentage \\
\hline NCDs & 6633 & 29.7 \\
Infectious & 11,847 & 53.1 \\
Maternal and nutrition & 2184 & 9.8 \\
Injuries & 1656 & 7.4 \\
Total & 22,320 & 100.0 \\
\hline
\end{tabular}


Table 3 Distribution of NCDs by residence, sex and age category, SNNPR, 2012-2014

\begin{tabular}{|c|c|c|c|}
\hline Variable & Category & Number & Column $\%$ \\
\hline \multirow[t]{2}{*}{ Residence } & Urban & 3779 & 57.0 \\
\hline & Rural & 2854 & 43.0 \\
\hline \multirow[t]{2}{*}{ Sex } & Male & 3594 & 54.2 \\
\hline & Female & 3039 & 45.8 \\
\hline \multirow[t]{17}{*}{ Age } & $<5$ & 176 & 2.7 \\
\hline & $5-9$ & 182 & 2.7 \\
\hline & $10-14$ & 241 & 3.6 \\
\hline & 15-19 & 562 & 8.5 \\
\hline & $20-24$ & 840 & 12.7 \\
\hline & $25-29$ & 915 & 13.8 \\
\hline & $30-34$ & 711 & 10.7 \\
\hline & $35-39$ & 644 & 9.7 \\
\hline & $40-44$ & 576 & 8.7 \\
\hline & $45-49$ & 486 & 7.3 \\
\hline & $50-54$ & 405 & 6.1 \\
\hline & $55-59$ & 227 & 3.4 \\
\hline & $60-64$ & 270 & 4.1 \\
\hline & $65-69$ & 124 & 1.9 \\
\hline & $70-74$ & 137 & 2.1 \\
\hline & $75-79$ & 47 & 0.7 \\
\hline & $80+$ & 90 & 1.4 \\
\hline Total & & 6633 & 100.0 \\
\hline
\end{tabular}

Table 4 Types of NCDs in selected health facilities, SNNPR, 2012-2014

\begin{tabular}{lll}
\hline Types of Non-communicable disease & Number & Percent \\
\hline Diabetes Mellitus & 870 & 13.1 \\
Epilepsy & 418 & 6.3 \\
Cancer & 316 & 4.8 \\
CVD & 1246 & 18.8 \\
Chronic Respiratory Disease & 389 & 5.9 \\
Digestive Disorder & 1775 & 26.8 \\
Mental Health Problem & 631 & 9.5 \\
BPH & 164 & 2.5 \\
Eye Disease & 186 & 2.8 \\
Autoimmune Diseases & 180 & 2.7 \\
Neurological disorder & 51 & 0.8 \\
Renal Disorder & 126 & 1.9 \\
Other NCDs & 281 & 4.2 \\
Total & 6633 & 100.0 \\
\hline
\end{tabular}

\section{Discussion}

This study was proposed to show the magnitude of NCDs in health facilities in SNNPR over three years and covered 23 health facilities of different types (primary, secondary and tertiary levels, and private and public owned facilities).

The overall magnitude of NCDs among reviewed 22,320 patient cards was $6633(29.7 \%)$ and was in line with WHO country profile report of 2014 [9] which reported $30 \%$ of burden comes from NCDs. It was also comparable with findings of study conducted in Nepal using facility based data [19] that reported overall prevalence of NCDS to be $31 \%$.

Evidences show that there is an increasing burden due to NCDs [5, 6, 8, 14, 20-28]. Different community based disease specific surveys on NCDs like diabetes and hypertension in Ethiopia also concluded that the prevalence of these diseases is high [28-41]. In this study, the overall prevalence of NCDs is also high and is alarming in country where infectious diseases are among major cause of morbidity and morbidity. Even though communicable diseases were the leading causes of morbidity in this study too, the magnitude of NCDs is also approaching to infectious diseases, being the next major causes of morbidity. While the prevalence of NCDs is high, it changed slightly over three years being 30.4, 28.8 and $28.7 \%$ for years 2012, 2013 and 2014 respectively. The slight change might be due to the short period of time included to see trend because of limited availability of data.

Even though the prevalence of NCDs is increasing, chronic NCDs in developing countries (including Ethiopia) have got little attention due to competing challenges $[6,20,42,43]$. In addition, lack of a national strategy for prevention and control of NCDs has been hampering coordination of activities and services to minimize potential risk factors and manage diseases [43].

Above studies conducted in Ethiopia [28-41] associated NCDs with different socio-demographic and socio-economic factors, more specifically with low awareness and poor practice and recommended policy and strategic actions that could minimize risk factors. Evidences show that many of NCDs related health-care interventions are cost effective if provided early, compared to costly procedures at advanced stages of diseases $[4,44]$, but many of acute interventions required to address NCDs are best provided at referral (hospital) level and require health workers with advanced training [4, $44,45]$. One of the key steps for prevention and control of NDCs is preparing national strategies to guide the control and prevention activities [45]. However, national guidelines (strategies) and appropriate care (technologies and medicines) for people with NCDs is lacking in low-income country, Ethiopia [43]. 


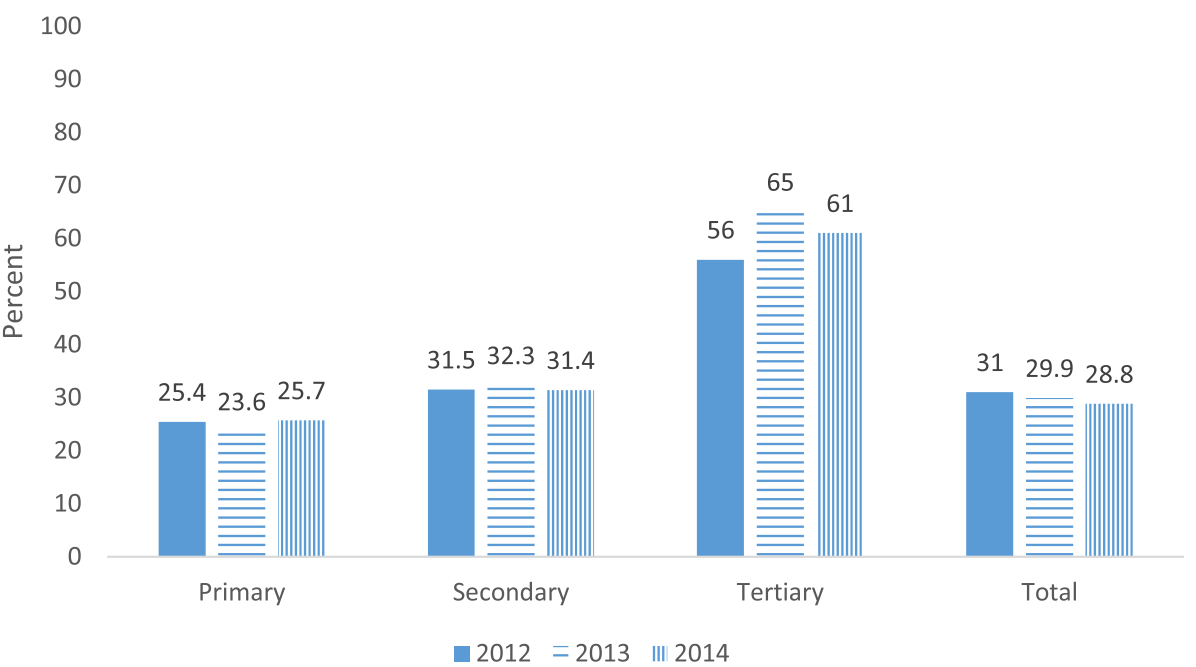

Fig. 1 Percent of NCDs in primary, secondary and tertiary level of health facilities, SNNPR, 2012-2014

Another thing that should be taken in to account is the distribution of NCDs was alarmingly comparable between urban and rural areas and attacking reproductive age group. Studies in other country [46] and in Ethiopia [37] also reported that NCDs are becoming problem of both urban and rural communities. So, health systems need to be further strengthened to deliver an effective, realistic and affordable package of interventions and services for people with NCDs.

This study was first comprehensive study on prevalence of NCDs in the region using relatively big samples and provides useful background data to stakeholders working on NCDs and researchers. As facility based retrospective study and due to its limited methods, this

Table 5 Causes of deaths in selected health facilities, SNNPR, 2012-2014

\begin{tabular}{llll}
\hline Causes of death & Frequency & Percent & Cumulative percent \\
\hline CVD & 9 & 12.5 & 12.5 \\
Malaria & 8 & 11.1 & 23.6 \\
Digestive Disorder & 7 & 9.7 & 41.7 \\
Pneumonia & 6 & 8.3 & 31.9 \\
Malnutrition & 4 & 5.6 & 47.2 \\
HIV/AIDS & 3 & 4.2 & 51.4 \\
Meningitis & 3 & 4.2 & 55.6 \\
Epilepsy & 3 & 4.2 & 59.7 \\
Fighting & 3 & 4.2 & 63.9 \\
Typhoid fever & 2 & 2.8 & 66.7 \\
TB & 2 & 2.8 & 69.4 \\
AFI & 2 & 2.8 & 72.2 \\
Cancer & 2 & 2.8 & 75.0 \\
Others & $18^{\mathrm{a}}$ & 25.0 & 100.0 \\
\hline
\end{tabular}

${ }_{\text {- all }} 18$ other causes of death were of different categories study has the following limitations. First, due to lack of organized data in regionally representative health facilities, trend presented was of short period. Second, the magnitude presented here was caseload of NCDs and didn't control recount of cases by revisit and referral. In addition, even though analysis of records may help to understand what went wrong (medical errors) and what measures could be taken to minimize such errors in the future [47], we used final diagnosis and didn't review symptoms, signs and classification due to limited logistics (money, time and human power). Finally, the proportion shown here may not represent true prevalence in community as it doesn't represent people who are not accessing healthcare (and died before accessing) due to different factors.

\section{Conclusion}

Health facilities are burdened with significant proportion of clients with NCDs. Young population accounts large share and NCDs are becoming public health problem of urban and rural area within a health care system that focus on communicable diseases. There is a need to strengthen the health system to work towards NCDs, and investigate risk factors associated with NCDs at individual level.

\section{Abbreviations}

BPH: Benign Prostatic Hyperplasia; CVD: Cardiovascular Disease; IBM: International Business Machines Corporation; NCDs: Non-Communicable Diseases; SNNPR: Southern Nations Nationalities and People's Region; SPSS: Statistical Package for the Social Sciences

Funding

This study was supported by SNNPR Health Bureau. The funder had no role in study design, data collection and analysis, decision to publish, or preparation of the manuscript. 


\section{Availability of data and materials}

All relevant data are within the manuscript. The datasets analyzed during the current study available from the corresponding author on reasonable request.

\section{Authors' contributions}

ME, EM, TD, KD, TM, SA, MS, TT and TG contributed to conception and design and acquisition of data. ME, TD and TG managed data and wrote report. ME finalized report and prepared manuscript. TG reviewed manuscript. EM and KD coordinated overall study. All authors read and approved the final manuscript.

\section{Ethics approval and consent to participate}

Ethical clearance was obtained from Ethical Review Committee of SNNPR Health Bureau. Administrative permission was obtained from regional health bureau and zonal health departments. No individual identifier data was collected and data was analyzed anonymously.

\section{Consent for publication}

Not applicable, no individual detail is presented.

\section{Competing interests}

The authors declare that they have no competing interests.

\section{Publisher's Note}

Springer Nature remains neutral with regard to jurisdictional claims in published maps and institutional affiliations.

\section{Author details}

${ }^{1}$ SNNPR Health Bureau, Hawassa, Ethiopia. ${ }^{2}$ College of Health Science and Medicine, Wolaita Sodo University, Wolaita Sodo, Ethiopia.

\section{Received: 15 January 2018 Accepted: 14 June 2018}

Published online: 04 July 2018

\section{References}

1. WHO. Noncommunicable diseases: WHO, Media center; [updated January 2015; cited 2016 10, Oct]. Available from: http://www.who.int/mediacentre/ factsheets/fs355/en/

2. Bloom DE, Cafero ET, Jané-Llopis E, Abrahams-Gessel S, Bloom LR, Fathima $\mathrm{S}$, et al. The global economic burden of noncommunicable diseases. Geneva: World Economic Forum; 2011.

3. WHO. Noncommunicable Diseases Country profiles 2011: World Health Organization; 2011.

4. Alwan A, Armstrong T, Bettcher D, Branca F, Chisholm D, Ezzati M, et al. Global status report on noncommunicable diseases 2010: WHO; 2011.

5. Mendis S, Armstrong T, Bettcher D, Branca F, Lauer J, Chestnov O. Global status report on noncommunicable diseases 2014: "Attaining the nine global noncommunicable diseases targets; a shared responsibility". Geneva: WHO; 2014.

6. Omoleke SA. Chronic non-communicable disease as a new epidemic in Africa: focus on the Gambia. Pan African Med J. 2013;14(87)

7. Ige O, Owoaje $\mathrm{E}$, Adebiyi $\mathrm{O}$. Non communicable disease and risky behaviour in an urban university community Nigeria. Afr Health Sci. 2013;13(1):62-7.

8. Misganaw A, Mariam DH, Ali A, Araya T. Epidemiology of major noncommunicable diseases in Ethiopia: a systematic review. J Health Popul Nutr. 2014;32(1):1-13.

9. WHO. Noncommunicable diseases country profiles 2014. Ethiopia: WHO; 2014.

10. Misganaw A, Mariam DH, Araya T. The double mortality burden among adults in Addis Ababa, Ethiopia, 2006-2009. Prev Chronic Dis. 2012;9:E84. Available at https://www.ncbi.n/m.nih.gov/pmc/articles/PMC3396553/.

11. Bekele A, Amenu K, Getachew T, Defar A, Tadesse M, Teklie H, et al. Ethiopia steps report on risk factors for chronic noncommunicable diseases and prevalence of selected ncds. Addis Ababa: Ethiopia Public Health Institute and $\mathrm{FMOH} ; 2016$.

12. Mathers C, Fat DM. The global burden of disease: 2004 update. Geneva: WHO; 2008.

13. Lim SS, Vos T, Flaxman AD, Danaei G, Shibuya K, Adair-Rohani H, et al. A comparative risk assessment of burden of disease and injury attributable to 67 risk factors and risk factor clusters in 21 regions,
1990-2010: a systematic analysis for the global burden of disease study 2010. Lancet. 2012;380(9859):2224-60.

14. SNNP Region Overview: Southern Nations, Nationalities and People's Regional State Health Bureau. http://www.snnprhb.gov.et/index.php?option= com_content\&view=article\&id=9:sexteneded\&catid=2:vision-mission\&ltemid=39. Accessed 25 April 2016

15. Annual performance review meeting of 2006 EFY Hawassa: Regional Health Bureau, 2014.

16. WHO. Health Facility Survey: Tool to evaluate the quality of care delivered to sick children attending outpatient facilities. Geneva: World Health Organization; 2003.

17. Anthony G. Turner, Gustavo Angeles, Amy O. Tsui, Marilyn Wilkinson, Robert Magnani. SAMPLING MANUAL for FACILITY SURVEYS: For Population, Maternal Health, Child Health and STD Programs in Developing Countries. MEASURE Evaluation; 2001.

18. FMoH. National Malaria Strategic Plan 2014-2020. Addis Ababa: Federal Democratic Republic of Ethiopia, Ministry of Health; 2014.

19. Bhandari GP, Angdembe MR, Dhimal M, Neupane S, Bhusal C. State of noncommunicable diseases in Nepal. BMC Public Health. 2014;14(23)

20. Prevett M. Chronic non-communicable diseases in Ethiopia-a hidden burden. Ethiopian Journal of Health Sciences. 2012;22(Spec Iss):1-2.

21. Negin J, Cumming R, de Ramirez SS, Abimbola S, Sachs SE. Risk factors for non-communicable diseases among older adults in rural Africa. Tropical Med Int Health. 2011;16(5):640-6.

22. Mayosi BM, Flisher AJ, Lalloo UG, Sitas F, Tollman SM, Bradshaw D. The burden of non-communicable diseases in South Africa. Lancet. 2009; 374(9693):934-47.

23. Robinson HM, Hort K. Non-communicable diseases and health systems reform in low- and middle-income countries. Pac Health Dialog. 2012;18(1):179-90.

24. Ghaffar A, Reddy KS, Singhi M. Burden of non-communicable diseases in South Asia. BMJ. 2004;328(7443):807-10.

25. Boutayeb A, Boutayeb S. The burden of non communicable diseases in developing countries. Int J Equity Health. 2005;4(2)

26. Boutayeb $\mathrm{A}$. The double burden of communicable and non-communicable diseases in developing countries. Trans R Soc Trop Med Hyg. 2006;100(3):191-9.

27. Dalal S, Beunza JJ, Volmink J, Adebamowo C, Bajunirwe F, Njelekela M, et al. Non-communicable diseases in sub-Saharan Africa: what we know now. Int J Epidemiol. 2011;40(4):885-901.

28. Animaw W, Seyoum Y. Increasing prevalence of diabetes mellitus in a developing country and its related factors. PLoS One. 2017;12(11):e0187670.

29. Muluneh AT, Haileamlak A, Tessema F, Alemseged F, Woldemichael K, Asefa $M$, et al. Population based survey of chronic non-communicable diseases at Gilgel gibe field research center, Southwest Ethiopia. Ethiopian Journal of Health Sciences. 2012;22(Spec Iss):7-18.

30. Kibret KT, Mesfin YM. Prevalence of hypertension in Ethiopia: a systematic meta-analysis. Public Health Rev. 2015;36:14

31. Asresahegn $H$, Tadesse $F$, Beyene E. Prevalence and associated factors of hypertension among adults in Ethiopia: a community based cross-sectional study. BMC Research Notes. 2017:10:629.

32. Demisse AG, Greffie ES, Abebe SM, Bulti AB, Alemu S, Abebe B, et al. High burden of hypertension across the age groups among residents of Gondar city in Ethiopia: a population based cross sectional study. BMC Public Health. 2017;17:647.

33. Worede A, Alemu S, Gelaw YA, Abebe M. The prevalence of impaired fasting glucose and undiagnosed diabetes mellitus and associated risk factors among adults living in a rural Koladiba town, Northwest Ethiopia. BMC Research Notes. 2017;10:251.

34. Gebrihet TA, Mesgna KH, Gebregiorgis YS, Kahsay AB, Weldehaweria NB, Weldu MG. Awareness, treatment, and control of hypertension is low among adults in Aksum town, northern Ethiopia: a sequential quantitativequalitative study. PLoS One. 2017;12(5):e0176904

35. Tesfaye T, Shikur B, Shimels T, Firdu N. Prevalence and factors associated with diabetes mellitus and impaired fasting glucose level among members of federal police commission residing in Addis Ababa, Ethiopia. BMC Endocr Disord. 2016;16:68

36. Angaw K, Dadi AF, Alene KA. Prevalence of hypertension among federal ministry civil servants in Addis Ababa, Ethiopia: a call for a workplacescreening program. BMC Cardiovasc Disord. 2015;15:76.

37. Abebe SM, Berhane Y, Worku A, Getachew A. Prevalence and associated factors of hypertension: a Crossectional community based study in Northwest Ethiopia. PLoS One. 2015;10(4):e0125210. 
38. Helelo TP, Gelaw YA, Adane AA. Prevalence and associated factors of hypertension among adults in Durame town, southern Ethiopia. PLoS One. 2014;9(11):e112790.

39. Abebe SM, Berhane Y, Worku A, Assefa A. Diabetes mellitus in north West Ethiopia: a community based study. BMC Public Health. 2014;14:97.

40. Alemseged F, Haileamlak A, Tegegn A, Tessema F, Woldemichael K, Asefa M, et al. Risk factors for chronic non-communicable diseases at Gilgel gibe field research center, Southwest Ethiopia: population based study. Ethiopian Journal of Health Sciences. 2012;22(Spec Iss):19-28.

41. Awoke A, Awoke T, Alemu S, Megabiaw B. Prevalence and associated factors of hypertension among adults in Gondar, Northwest Ethiopia: a community based cross-sectional study. BMC Cardiovasc Disord. 2012;12:113.

42. Dermot Maher, Anthony D Harries, Rony Zachariah, Don Enarson. A global framework for action to improve the primary care response to chronic noncommunicable diseases: a solution to a neglected problem. BMC Public Health 2009;9(355).

43. Ali A. Commendable approach to mitigate double burden. Ethiop J Health Dev. 2010;24(3)

44. Joshi R, Alim M, Kengne AP, Jan S, Maulik PK, Peiris D, et al. Task shifting for non-communicable disease management in low and middle income countries-a systematic review. PLoS One. 2014;9(8):e103754.

45. Daar AS, Singer PA, Persad DL, Pramming SK, Matthews DR, Beaglehole R, et al. Grand challenges in chronic non-communicable diseases. Nature. 2007; 450(7169):494-6.

46. Yang J, Yu W, Zhou Q, Mahapatra T, Li Y, Zhang X, et al. Burden and correlates of non-communicable-diseases among rural residents: a crosssectional study in Hebei, China. BMC Public Health. 2015;15:571.

47. Sarkar S, Seshadri D. Conducting record review studies in clinical practice. Journal of Clinical and Diagnostic Research : JCDR. 2014;8(9):JG01-JG4.

\section{Ready to submit your research? Choose BMC and benefit from:}

- fast, convenient online submission

- thorough peer review by experienced researchers in your field

- rapid publication on acceptance

- support for research data, including large and complex data types

- gold Open Access which fosters wider collaboration and increased citations

- maximum visibility for your research: over $100 \mathrm{M}$ website views per year 